\title{
Cancer risk factors and screening in the off-reserve First Nations, Métis and non-Aboriginal populations of Ontario
}

\author{
D. R. Withrow, MSc (1, 2); A. Amartey, MPH (1); L. D. Marrett, PhD (1, 2)
}

This article has been peer reviewed.

\begin{abstract}
Introduction: This study describes the prevalence of smoking, obesity, sedentary behaviour/physical activity, fruit and vegetable consumption and alcohol use as well as the uptake of breast, cervical and colorectal cancer screening among First Nations and Métis adults in Ontario and compares these to that of the non-Aboriginal population.
\end{abstract}

Methods: We used the Canadian Community Health Survey (2007 to 2011 combined) to calculate prevalence estimates for the 3 ethnocultural populations.

Results: First Nations and Métis adults were significantly more likely than nonAboriginal adults to self-report smoking and/or to be classified as obese. Alcohol use exceeding cancer prevention recommendations and inadequate fruit and vegetable consumption were more common in First Nations people than in the non-Aboriginal population. First Nations women were more likely to report having had a Fecal Occult Blood Test in the previous 2 years than non-Aboriginal women. No significant differences across the 3 ethnocultural groups were found for breast and cervical screening among women or colorectal screening among men.

Conclusion: Without intervention, we are likely to continue to see a significant burden of smoking- and obesity-related cancers in Ontario's Aboriginal population.

Keywords: cancer, chronic disease, American native continental ancestry group, risk factors, mass screening, indigenous population, First Nations, Métis, Ontario

\section{Introduction}

Cancer is one of the leading causes of death among Aboriginal people. ${ }^{1}$ Historically, cancer was less common in Aboriginal people in Canada, but cancer incidence is increasing at a rate exceeding that of the non-Aboriginal population, for whom cancer rates have been relatively stable over the last 20 years. ${ }^{2,3}$ Knowing the prevalence of cancer risk factors and the uptake of cancer screening in Aboriginal subpopulations is important to be able to support the development of Aboriginal-focused cancer control and prevention strategies.
Population-based health surveys are a common source of data to assess risk factor prevalence in the general population. However, their use for studying Aboriginal health has proved challenging. While several surveys in recent years have included ethnocultural variables to identify respondents as Aboriginal, national population-based health surveys typically sample a relatively small number of Aboriginal people. With health service delivery for Aboriginal peoples increasingly shifting toward provincial jurisdiction, ${ }^{4}$ provincial health statistics for subpopulations are necessary. Stratifying national population-based surveys by pro- vince, however, further limits the number of Aboriginal respondents available. For example, although Ontario has the largest Aboriginal population in Canada, about 200000 First Nations and 86000 Métis, ${ }^{5}$ the number of Aboriginal people sampled by national surveys such as the Canadian Community Health Survey (CCHS) remains low. The CCHS samples about 21000 respondents from Ontario each year, of whom about 600 self-identify as Aboriginal, a number insufficient to produce interpretable and meaningful Ontario First Nations- and Métis-specific estimates for any single survey year.

To overcome the problem of small samples, our paper builds on recent work by Statistics Canada by pooling multiple survey years of the CCHS. ${ }^{6}$ We have added to this work by including more recent data from 2011, by focusing specifically on cancer-related risk factors, by estimating the uptake of cancer screening modalities, and by considering the impact of sociodemographic factors. Specifically, our work aims to (1) measure the prevalence of smoking, obesity, physical activity/sedentariness, fruit and vegetable intake and alcohol use in Ontario First Nations and Métis and to compare these risk factors for cancer ${ }^{7-12}$ with those in the non-Aboriginal population, and (2) measure the prevalence of up-to-date colorectal, breast and cervical screening in Ontario First Nations and Métis and compare these to screening rates in the non-Aboriginal population. In both instances, we have considered the impact of sociodemographic factors. With this analysis, we hope to highlight areas for action in Aboriginal cancer control and

\section{Author references:}

1. Surveillance and Prevention, Prevention and Cancer Control, Cancer Care Ontario, Toronto, Ontario, Canada 2. Department of Epidemiology, Dalla Lana School of Public Health, University of Toronto, Toronto, Ontario, Canada

Correspondence: Diana R. Withrow, Surveillance and Prevention, Prevention and Cancer Control, Cancer Care Ontario, 505 University Ave, Toronto, ON M5G 1X3; Tel.: 416-971-9800, ext. 3125; Fax: 416-971-6888; Email: diana.withrow@cancercare.on.ca 
provide a baseline against which future measures of these constructs can be compared.

\section{Methods}

\section{Data source}

This study draws on data collected by Statistics Canada between 2007 and 2011 through the CCHS. The target population of this survey was people aged 12 years and older in the 10 provinces and territories excluding those living in institutions, in the Quebec health regions of Nunavik and Terres-Cries-de-la-Baie-James, or on reserve or in other Aboriginal settlements in the provinces. Survey respondents were sampled from the population at large using 3 sampling frames, with $99 \%$ of the sample selected using an area- or telephone-based sampling frame. About $1 \%$ of the sample was identified through random digit dialing. The survey was conducted with computer-assisted interviewing with an approximately equal number of respondents surveyed in person as by phone. ${ }^{13}$

For this report, we restricted the sample to adult respondents in the province of Ontario. Between 2007 and 2011, the response rate in Ontario varied from $68.7 \%$ to $73.6 \% .^{13}$ To increase the number of First Nations and Métis responses eligible for analysis, the microdata files from all 5 annual releases of CCHS data from 2007 to 2011 were combined and prevalence estimates were calculated for all 5 years combined as per the methodology described by Statistics Canada. ${ }^{14}$

\section{Measuring risk factors and screening}

We calculated the prevalence of 6 risk factors and 3 screening modalities. Unless otherwise specified, risk factor analyses included respondents aged 18 years and over. Respondents with a missing or invalid response to a given question were excluded from the denominator of that indicator. Age limits and response cut-off points for each screening measure were based on Ontario guidelines for that screening modality. ${ }^{15-17}$ For sedentary behaviour and breast and cervical screen- ing, relevant questions were only posed in the 2007, 2008 and 2011 surveys.

The definitions of each indicator are described in more detail below.

- We defined the smoking indicator as the proportion of respondents aged 20 years and over who reported that they smoked daily or occasionally. A cut-off age of 20 years was used to be consistent with other Ontario public health indicators. ${ }^{18}$

- We defined the obesity indicator as the proportion of respondents who, based on self-reported height and weight, had a body mass index (BMI) of $30 \mathrm{~kg} / \mathrm{m}^{2}$ or more. Pregnant and lactating women were excluded.

- We defined the sedentary behaviour indicator as the proportion of respondents who spent at least 11 hours per week on a computer and/or at least 15 hours per week watching television outside of school or work.

- We defined the leisure time physical activity indicator as the proportion of respondents classified as either moderately active or active during leisure time in the previous 3 months, based on a daily estimated energy expenditure (EE) exceeding $1.5 \mathrm{kcal} / \mathrm{kg} /$ day. To determine $\mathrm{EE}$, respondents were asked about the frequency and duration of different activities, such as swimming, ice-skating, volleyball, etc. EE was calculated by combining this information with the metabolic equivalent of the activity, which takes into account intensity of the activity.

- We defined the fruit and vegetable intake indicator as the proportion of respondents who consumed fruit or vegetables, excluding potatoes, at least 5 times per day based on an abridged food frequency questionnaire. Like the CCHS documentation, which uses times and servings interchangeably, we mainly use the term servings throughout this paper, but note that the CCHS asks respondents how many times they have eaten a given fruit or vegetable within the recall period.

- We defined the average daily alcohol consumption indicator as the proportion of female respondents who drank, on average, more than 1 drink per day and the proportion of male respondents who drank, on average, more than 2 drinks per day in the week preceding the interview. This cut-off was based on cancer prevention recommendations that suggest consuming no more than this amount. ${ }^{19}$ Pregnant women were excluded.

- We defined the cervical cancer screening indicator as the proportion of women aged 21 to 69 years who reported having had a Pap smear test in the previous 3 years.

- We defined the breast cancer screening indicator as the proportion of women aged 50 to 74 years who reported having had a mammogram in the previous 2 years. To capture mammograms for the purposes of screening rather than as diagnostic investigations, we excluded those women who reported having had a mammogram because of a previously detected lump, follow-up of breast cancer treatment, breast problem or "other [non-screening] reason."

- We calculated 2 indicators for colorectal cancer screening. First, we measured the proportion of respondents aged 50 to 74 years who reported having had a Fecal Occult Blood Test (FOBT) in the previous 2 years. Second, we calculated the proportion of adults in that age range who had not had an FOBT in the previous 2 years, or a colonoscopy and/ or sigmoidoscopy in the previous 10 years, and were accordingly due for colorectal cancer screening.

\section{Aboriginality}

From 2007 to 2010, all CCHS respondents were asked, "Are you an Aboriginal person, that is, North American Indian, Métis or Inuit?"' If the respondent said yes, he or she would be asked to specify the subpopulation to which he or she belonged. In 2011, this question was only posed to those respondents who had previously reported that they were born in Canada, the United States, Germany or Greenland. To be consistent, we classified 2007 to 2010 respondents as First Nations and Métis only if they had also reported being born in one of these four countries. ${ }^{20}$

We used mutually exclusive ethnocultural categories despite that respondents could report multiple Aboriginal identities. For 
example, any respondent who replied that they were First Nations only or First Nations and Inuit was classified as First Nations. Any respondent who replied that they were Métis only or Métis and any other Aboriginal identity was classified as Métis. Due to small sample sizes, we did not generate Inuit-specific estimates in this report. Our definitions of First Nations and Métis are further illustrated in Table 1.

\section{Statistical analysis}

The CCHS has a multi-stage, complex sampling design. Sampling weights assigned by Statistics Canada are used to account for selection probability, nonresponse and non-coverage. For this report, weights were also adjusted to take into account the amalgamation of several survey cycles. ${ }^{14}$ We used bootstrapping techniques to calculate the coefficient of variation (CV) and 95\% confidence intervals (CIs). In accordance with Statistics Canada regulation, estimates with a CV ranging from $16.6 \%$ to $33.3 \%$ are flagged to be interpreted with caution. Those with a $\mathrm{CV}$ greater than $33.3 \%$ are suppressed because of extreme sampling variability.

Estimates were age-standardized to the age structure of the Ontario Aboriginal identity population in the 2006 Census using the age groups 20 to 24,25 to 44,45 to 64 , and 65 years and over. For those indicators whose cut-off points for age did not line up with those provided by the census, age-standardization was to the nearest age group (e.g. 18- and 19-year olds were standardized to the 20- to 24year age group).

We used logistic regression to generate odds ratios (ORs) of risk factor prevalence and uptake of screening in First Nations and Métis compared with the nonAboriginal Ontario population. We present sex-specific age-adjusted ORs and ORs adjusted for age, income quintile, education and rural/urban place of residence as reported in the CCHS. CCHS survey year was controlled in both models. Estimates were considered statistically significantly different from the reference if the $95 \%$ CIs of the OR did not overlap with 1.00.

\section{Results}

Combining 5 years of Ontario CCHS data yielded 90866 respondents aged 18 years and over for analysis, of whom 1468 identified as off-reserve First Nations and 990 as Métis. The demographic characteristics of respondents belonging to each ethnocultural group are summarized in Table 2. The First Nations and Métis populations were younger than the nonAboriginal population, had less schooling and lower income, and were more likely to live in a rural setting rather than an urban one.

\section{TABLE 1}

Definitions of First Nations (off-reserve), Métis and non-Aboriginal identity based on Canadian Community Health Survey responses

\begin{tabular}{|c|c|c|c|c|c|}
\hline & \multirow[t]{2}{*}{ Aboriginal identity } & \multicolumn{4}{|c|}{ Subgroup identity } \\
\hline & & Single & & tiple & \\
\hline \multirow{2}{*}{ First Nations (off-reserve) } & Yes & First Nations & & & \\
\hline & Yes & & First Nations & & Inuit \\
\hline \multirow{4}{*}{ Métis } & Yes & Métis & & & \\
\hline & Yes & & First Nations & Métis & \\
\hline & Yes & & & Métis & Inuit \\
\hline & Yes & & First Nations & Métis & Inuit \\
\hline \multirow{2}{*}{ Non-Aboriginal } & No & \multicolumn{4}{|c|}{ Born in any country } \\
\hline & Yes & \multicolumn{4}{|c|}{ Born outside of Canada, USA, Germany, Greenland } \\
\hline
\end{tabular}

\section{Risk factors}

Table 3 and Figures 1 and 2 show prevalence estimates of risk factors and screening uptake while Table 4 shows odds ratios. The most notable differences in risk factor prevalence between First Nations, Métis and non-Aboriginal people were related to smoking and obesity. Offreserve First Nations and Métis men were more than twice as likely to report smoking than their non-Aboriginal peers (First Nations OR $=2.33$, 95\% CI: 1.79 3.02; Métis OR $=2.09$, 95\% CI: $1.54-$ 2.83), with $44.9 \%$ (95\% CI: 39.1-50.7) of First Nations men and $42.9 \%$ (95\% CI: 36.1-49.6) of Métis men smoking compared with $26.2 \%$ (95\% CI: 25.3-27.1) of non-Aboriginal men. Despite lower smoking prevalence in women, the disparity between ethnicities exceeded that in men. First Nations women were about 3.5 $(\mathrm{OR}=3.56,95 \% \mathrm{CI}: 2.75-4.61)$ times more likely to smoke than non-Aboriginal women and Métis women were about 2.5 (OR: 2.47, 95\% CI: 1.86-3.28) times more likely to smoke than non-Aboriginal women. Compared with non-Aboriginal people, First Nations and Métis were both about twice as likely to be classified as obese. Obesity rates ranged from $16.0 \%$ in non-Aboriginal women to $33.4 \%$ in First Nations men.

First Nations men and women were significantly less likely than nonAboriginal people to consume at least 5 servings of fruit and vegetables daily (male OR $=0.72,95 \%$ CI: 0.54-0.97; female $\mathrm{OR}=0.64,95 \% \mathrm{CI}: 0.51-0.81$ ), although this difference was not significant in men after accounting for sociodemographic differences. There were no significant differences in fruit and vegetable intake between Métis and nonAboriginal men and women.

First Nations and Métis men were about $50 \%$ more likely than non-Aboriginal men to surpass the recommended daily limits of alcohol consumption for cancer prevention (First Nations OR $=1.50$, 95\% CI: $1.08-$ 2.07; Métis OR 1.57, 95\% CI: 1.06-2.31). This difference was no longer statistically significant in Métis after taking into account sociodemographic differences, however. There was a trend toward increased alcohol 
TABLE 2

Sociodemographic characteristics of Ontario respondents to the CCHS, $\geq 18$ years, by Aboriginal identity (off-reserve population), 2007-2011 CCHS combined data

\begin{tabular}{|c|c|c|c|c|c|}
\hline \multirow[t]{2}{*}{ Characteristics } & \multirow[t]{2}{*}{$\begin{array}{l}\text { Non-Aboriginal } \\
(\mathrm{N}=88 \text { 408) }\end{array}$} & \multicolumn{2}{|c|}{$\begin{array}{l}\text { First Nations (off-reserve) } \\
\qquad(\mathrm{n}=1468)\end{array}$} & \multicolumn{2}{|c|}{$\begin{array}{c}\text { Métis } \\
(\mathrm{n}=990)\end{array}$} \\
\hline & & $\%$ & $p$ value $^{\mathrm{a}}$ & $\%$ & $p$ value $^{\mathrm{a}}$ \\
\hline \multicolumn{6}{|l|}{ Sex } \\
\hline Male & 48.8 & 48.1 & & 46.0 & \\
\hline Female & 51.2 & 51.9 & .720 & 54.0 & .295 \\
\hline \multicolumn{6}{|l|}{ Age group, years } \\
\hline $18-24$ & 12.3 & 16.6 & & 10.5 & \\
\hline $25-44$ & 36.0 & 41.5 & & 46.5 & \\
\hline $45-64$ & 35.0 & 34.5 & & 35.1 & \\
\hline$\geq 65$ & 16.7 & 7.4 & $<.001$ & 8.0 & $<.001$ \\
\hline \multicolumn{6}{|l|}{ Education } \\
\hline Less than Secondary & 12.8 & 22.3 & & 21.6 & \\
\hline Secondary / Some post-secondary & 26.3 & 30.2 & & 28.8 & \\
\hline Post-secondary & 61.0 & 47.5 & $<.001$ & 49.6 & $<.001$ \\
\hline \multicolumn{6}{|l|}{ Income quintiles } \\
\hline 1 (Lowest) & 18.3 & 33.1 & & 19.3 & \\
\hline 2 & 19.7 & 18.6 & & 24.1 & \\
\hline 3 & 20.3 & 17.0 & & 20.9 & \\
\hline 4 & 20.5 & 18.0 & & 18.8 & \\
\hline 5 (Highest) & 21.3 & 13.3 & $<.001$ & 16.9 & .097 \\
\hline \multicolumn{6}{|l|}{ Place of residence $^{b}$} \\
\hline Urban & 89.5 & 81.1 & & 78.4 & \\
\hline Rural & 10.5 & 18.9 & $<.001$ & 21.6 & $<.001$ \\
\hline
\end{tabular}

Source: Canadian Community Health Survey (2007-2011 combined), Statistics Canada.

Abbreviations: CA, Census Agglomeration; CCHS, Canadian Community Health Survey; CMA, Census Metropolitan Area.

${ }^{a} p$ values were generated through a $\chi^{2}$ test for difference in proportions between the First Nations and the non-Aboriginal populations and the Métis and non-Aboriginal populations respectively.

b Urban place of residence includes respondents living in a CMA, a Tracted CA, or a Non-Tracted CA. Rural place of residence includes non-CMA and non-CA locations.

consumption in First Nations and Métis women relative to non-Aboriginal women, but a statistically significant difference between First Nations and non-Aboriginal women emerged only after accounting for sociodemographic characteristics. While controlling for sociodemographic characteristics occasionally changed the statistical significance of a finding, it did not appreciably affect our interpretation of the odds ratios overall.

\section{Screening uptake}

In women, there was no statistically significant difference in uptake of mammographic or cervical cancer screening between the 3 ethnocultural groups. Most women had undergone a Pap smear test in the previous 3 years $(76.8 \%$ of First Nations, $72.3 \%$ of Métis and $78.0 \%$ of non-Aboriginal women). Fewer women, however, reported having had a mammogram in the previous 3 years, with fewer than $60 \%$ of First Nations and Métis women having done so, compared with nearly $70 \%$ of non-Aboriginal women.

About half of the respondents were due for colorectal cancer screening, having not had an FOBT in the previous 2 years or colonoscopy and/or sigmoidoscopy in the previous 10 years. Rates of underscreening were lower among women, and especially low (although the difference was not statistically significant) in First Nations women, among whom 38.8\% were underscreened. This difference could be attributed to the apparent increased uptake of FOBT among First Nations women, who were almost twice as likely $(\mathrm{OR}=1.78,95 \% \mathrm{CI}: 1.22-2.59)$ to have undergone the test compared with their non-Aboriginal peers.

\section{Discussion}

Analysis of the 2007 to 2011 CCHS revealed notable differences in the prevalence of certain cancer risk factors and uptake of cancer screening between Ontario's First Nations, Métis and nonAboriginal populations.

Most notably, smoking and obesity were significantly more prevalent in First Nations and Métis, an observation that has been reported at national and provincial levels. ${ }^{21-26}$ Data collected on First Nations reserves show a greater disparity, with on-reserve First Nations reporting higher rates of smoking and obesity than off-reserve populations. ${ }^{25,26}$ Despite evidence suggesting decreasing rates of smoking and obesity in off-reserve Aboriginal populations between 2001 and $2008,{ }^{27}$ the prevalence of these 2 risk factors remains significantly higher than that in the general population. Much of the rapid increase in cancer within the Aboriginal population is attributed to the increasing incidence of lung and colorectal cancers, $^{27-29}$ both of which have been linked to tobacco smoking and colorectal cancer to obesity. ${ }^{7,8,30}$ It is therefore imperative that interventions that reduce these negative risk factors within the Aboriginal population be a priority.

The analyses also showed lower prevalence of adequate fruit and vegetable intake and higher prevalence of alcohol consumption among First Nations compared with the non-Aboriginal population. Previous evidence has shown that, in addition to decreased fruit and vegetable consumption, off-reserve First Nations women had a higher average daily caloric intake, Aboriginal women ate fewer servings of grain, and Aboriginal men had fewer servings of dairy compared with the general population. ${ }^{31}$ This is of concern as several studies have found a link between an unhealthy diet and increased risk of cancer. $^{10}$ 
TABLE 3

Age-standardized prevalence of selected risk factors and cancer screening uptake for adult population ( $\geq 18$ years unless otherwise specified), by Aboriginal identity, off-reserve population, Ontario, 2007-2011 CCHS combined data

\begin{tabular}{|c|c|c|c|c|c|c|c|c|c|c|c|c|}
\hline \multirow[b]{3}{*}{ Indicator } & \multicolumn{6}{|c|}{ Males } & \multicolumn{6}{|c|}{ Females } \\
\hline & \multicolumn{2}{|c|}{ Non-Aboriginal } & \multicolumn{2}{|c|}{$\begin{array}{l}\text { First Nations } \\
\text { (off-reserve) }\end{array}$} & \multicolumn{2}{|c|}{ Métis } & \multicolumn{2}{|c|}{$\begin{array}{c}\text { Non- } \\
\text { Aboriginal }\end{array}$} & \multicolumn{2}{|c|}{$\begin{array}{l}\text { First Nations } \\
\text { (off-reserve) }\end{array}$} & \multicolumn{2}{|c|}{ Métis } \\
\hline & $\%$ & $95 \% \mathrm{Cl}$ & $\%$ & $95 \% \mathrm{Cl}$ & $\%$ & $95 \% \mathrm{Cl}$ & $\%$ & $95 \% \mathrm{Cl}$ & $\%$ & $95 \% \mathrm{Cl}$ & $\%$ & $95 \% \mathrm{Cl}$ \\
\hline \multicolumn{13}{|l|}{ Risk/protective factors } \\
\hline Daily or occasional smoker & 26.2 & $25.3-27.1$ & 44.9 & $39.1-50.7$ & 42.9 & $36.1-49.6$ & 17.8 & $17.2-18.4$ & 43.2 & $37.1-49.4$ & 35.1 & $28.7-41.5$ \\
\hline Obese & 18.9 & 18.2-19.6 & 33.4 & $27.2-39.5$ & 27.8 & $21.3-34.4$ & 16.0 & $15.4-16.6$ & 25.8 & $21.3-30.4$ & 25.6 & $17.6-33.6$ \\
\hline Physically Active & 52.4 & $51.5-53.4$ & 58.9 & $52.9-64.9$ & 53.2 & $46.7-59.7$ & 46.6 & $45.8-47.4$ & 50.1 & $44.5-55.7$ & 51.4 & $43.6-59.1$ \\
\hline$\geq 5$ servings of fruit and vegetables / day & 29.4 & $28.6-30.1$ & 23.5 & 18.3-28.7 & 23.7 & $18.1-29.2$ & 42.6 & $41.8-43.4$ & 31.4 & $26.4-36.3$ & 35.8 & $28.9-42.7$ \\
\hline$>1$ or 2 alcoholic drinks/day ${ }^{b}$ & 9.8 & $9.3-10.3$ & 14.3 & $10.4-18.1$ & 16.4 & $11.5-21.3$ & 8.6 & $8.1-9.1$ & 10.6 & 7.8-13.5 & $10.2^{\mathrm{E}}$ & $6.2-14.2$ \\
\hline \multicolumn{13}{|l|}{ Screening uptake } \\
\hline Mammogram in the previous 2 years $^{\mathrm{a}}$ & & - & & - & & - & 67.9 & $56.8-69.9$ & 59.7 & $47.1-72.3$ & 59.2 & $45.6-72.7$ \\
\hline
\end{tabular}

Source: Canadian Community Health Survey (2007-2011 combined), Statistics Canada.

Abbreviations: CCHS, Canadian Community Health Survey; Cl, confidence interval; FOBT, Fecal Occult Blood Test.

Notes: All estimates are age-standardized to the 2006 Ontario Aboriginal identity population. Estimates represent the adult population ( $\geq 18$ years) with the exception of the following

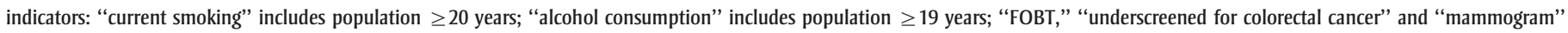
include population 50-74 years; "Pap smear test" includes population 21-69 years.

${ }^{a}$ Indicator not included in the 2009 and 2010 CCHS surveys. Estimates for these indicators represent 2007, 2008 and 2011 CCHS combined data.

b $>1$ drink/day on average in women; $>2$ drinks/day on average in men.

c Represents the percentage of respondents who have not had an FOBT in the previous 2 years nor a colonoscopy and/or sigmoidoscopy in the previous 10 years.

E Estimate should be interpreted with caution. Coefficient of variation is between $16.6 \%$ and $33.29 \%$.

We are not aware of any study of Aboriginal people in Canada that used an indicator of alcohol consumption based on cancer prevention recommendations similar to the one we used, although increased frequency of binge drinking in Ontario's First Nations and Métis populations has been reported. ${ }^{5,23}$ With earlier data showing a lower prevalence of heavy alcohol use among Aboriginal people compared with the general population, ${ }^{22}$ our findings along with other more recent data ${ }^{6,24}$ suggest an increasing pattern of risky drinking within the Aboriginal population over time.

No significant differences in breast and cervical cancer screening use were found across the 3 ethnocultural groups. There was a trend towards lower rates of mammography use in First Nations and Métis women, but notably, none of the ethnocultural groups reached the national target of $70 \%$ coverage. $^{32}$ Data on mammography uptake by Aboriginal women is limited, but a Manitoba-based study reported significantly lower uptake in onreserve First Nations women compared with women in rural areas. ${ }^{33}$ In addition, an earlier study suggested that members of the visible minorities in Canada were less likely than whites to report having had a mammogram. ${ }^{34}$

Consistent with earlier research, our study found that $70 \%$ of women reported having had a Pap smear test in the previous 3 years. $^{34}$ Despite adequate screening, however, the burden of cervical cancer among Aboriginal women is disproportionately high, suggesting that more or different preventive actions may be warranted. ${ }^{35}$

Compared with non-Aboriginal women, First Nations women were significantly more likely to report having had an FOBT in the previous 2 years and were less likely to be underscreened for colorectal cancer after taking into account colonoscopy and sigmoidoscopy. The 2 colorectal cancer screening indicators interpreted together suggest a stronger propensity for FOBT uptake (as opposed to a colonoscopy or sigmoidoscopy) in the First Nations population compared with both the Métis and non-Aboriginal populations. This uptake could be attributed, at least in part, to Cancer Care Ontario's 2008/09 implementation of an educational initiative to raise awareness about colorectal cancer, prevention and FOBT screening in First Nations communities. ${ }^{36}$

Social factors are particularly important to consider when studying Aboriginal health. Aboriginal people in Canada are more likely to live in poverty, report lower 
FIGURE 1

Prevalence of selected risk factors and up-to-date colorectal screening uptake for adult male population, $\geq 18$ years, by Aboriginal identity, off-reserve population, Ontario, 2007-2011 CCHS combined data

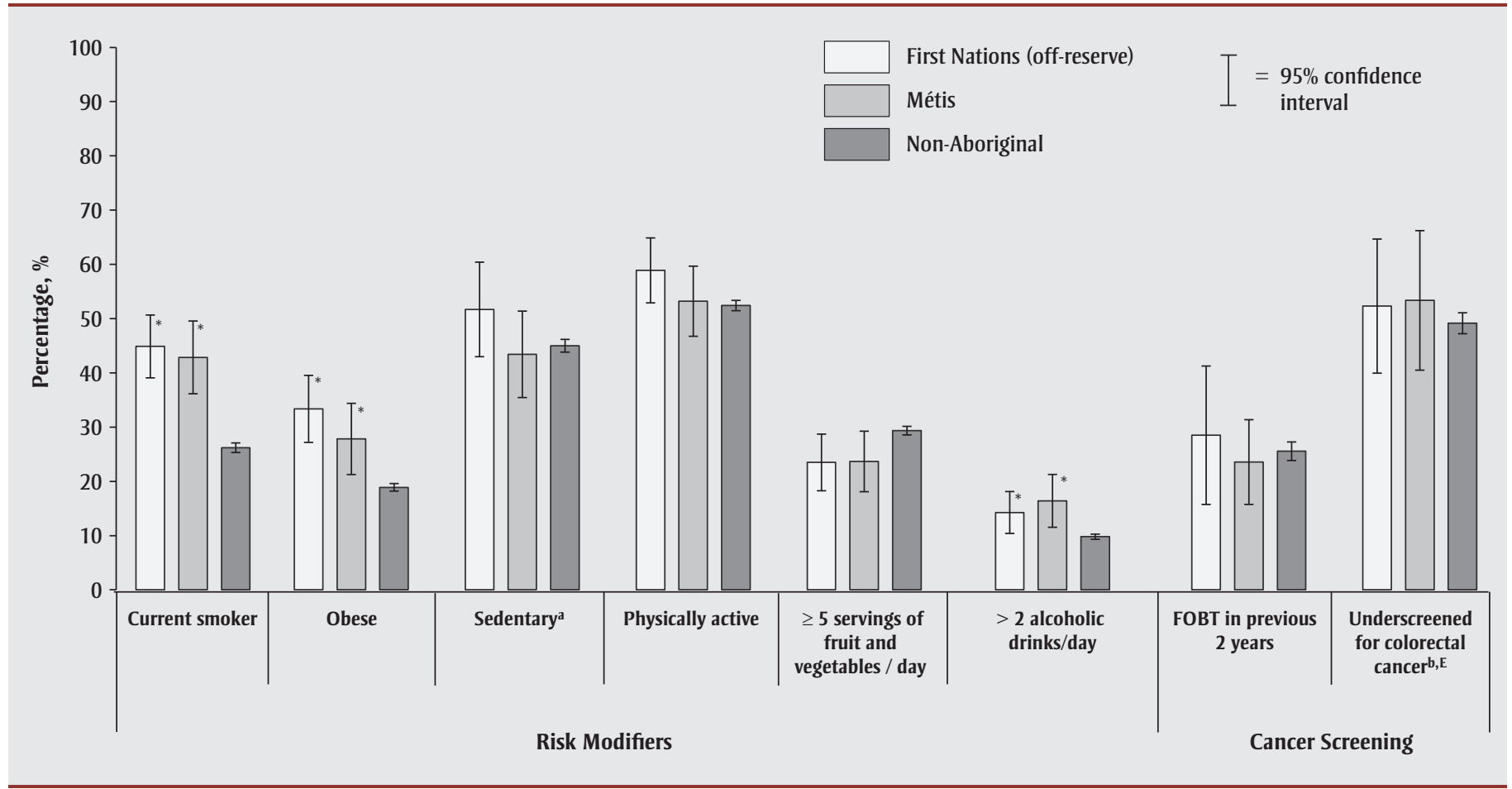

Source: Canadian Community Health Survey (2007-2011 combined), Statistics Canada.

Abbreviations: CCHS, Canadian Community Health Survey; FOBT, Fecal Occult Blood Test.

Notes: All estimates are age-standardized to the 2006 Ontario Aboriginal identity population. Estimates represent the adult population ( $\geq 18$ years) with the exception of the following

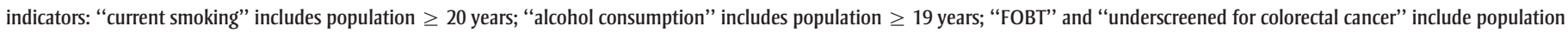
aged $50-74$ years.

${ }^{\text {a }}$ Indicator not included in the 2009 and 2010 CCHS surveys. Estimates for sedentary behaviour represent 2007, 2008, and 2011 CCHS combined data.

${ }^{b}$ Represents the percentage of respondents who had not had either of an FOBT in the previous 2 years or a colonoscopy and/or sigmoidoscopy in the previous 10 years.

${ }^{\mathrm{E}}$ Estimates for First Nations and Métis should be interpreted with caution. Coefficient of variation is between $16.6 \%$ and $33.29 \%$.

* Based on non-overlapping confidence intervals, estimate is significantly different from non-Aboriginal estimate for the corresponding risk factor.

household income, and experience lower educational achievement compared with non-Aboriginal people. ${ }^{21,23,37}$ In addition, First Nations and Métis are more likely to live in rural areas and rural residence has been associated with difficulty accessing health services and increased likelihood of smoking, excess weight and poor self-rated health. ${ }^{38}$ Nevertheless, we explored the impact of income, education and rural/ urban status and found very little change in the likelihood of reporting risk factors and screening uptake in the Aboriginal population compared with the non-Aboriginal population after taking these into account. This suggests the robustness of ethnicity as a determinant of health-related lifestyle factors in the First Nations and Métis.

\section{Strengths and limitations}

Although ethnicity, socioeconomic status and place of residence are known determinants of common chronic disease risk factors, we were unable to consider other important determinants of health and disease in this study. For example, more distal factors such as the health care system, racism and social capital have important indirect effects on Aboriginal health but these factors cannot be taken into account using CCHS data. ${ }^{23,39}$ In addition, we were only able to examine the prevalence of each risk factor individually and did not assess the relationships between them. For example, we estimated the prevalence of physical activity, diet and obesity, and though we know that physical activity and diet are strong determinants of obesity, ${ }^{40}$ we did not explore their relationship in this study. This gap presents an opportunity for researchers to consider multiple related risk factors and chronic diseases in Aboriginal and non-Aboriginal populations through causal modelling.

The exclusion of individuals living onreserve from the CCHS is another limitation of this work. Evidence from the First Nations Regional Health Survey, a survey of on-reserve First Nations, suggests that in addition to a higher prevalence of smoking and obesity in on-reserve communities, physical activity appears to be 
FIGURE 2

Prevalence of selected risk factors and up-to-date mammogram, cervical and colorectal screening uptake for adult female population, $\geq 18$ years, by Aboriginal identity, off-reserve population, Ontario, 2007-2011 CCHS combined data

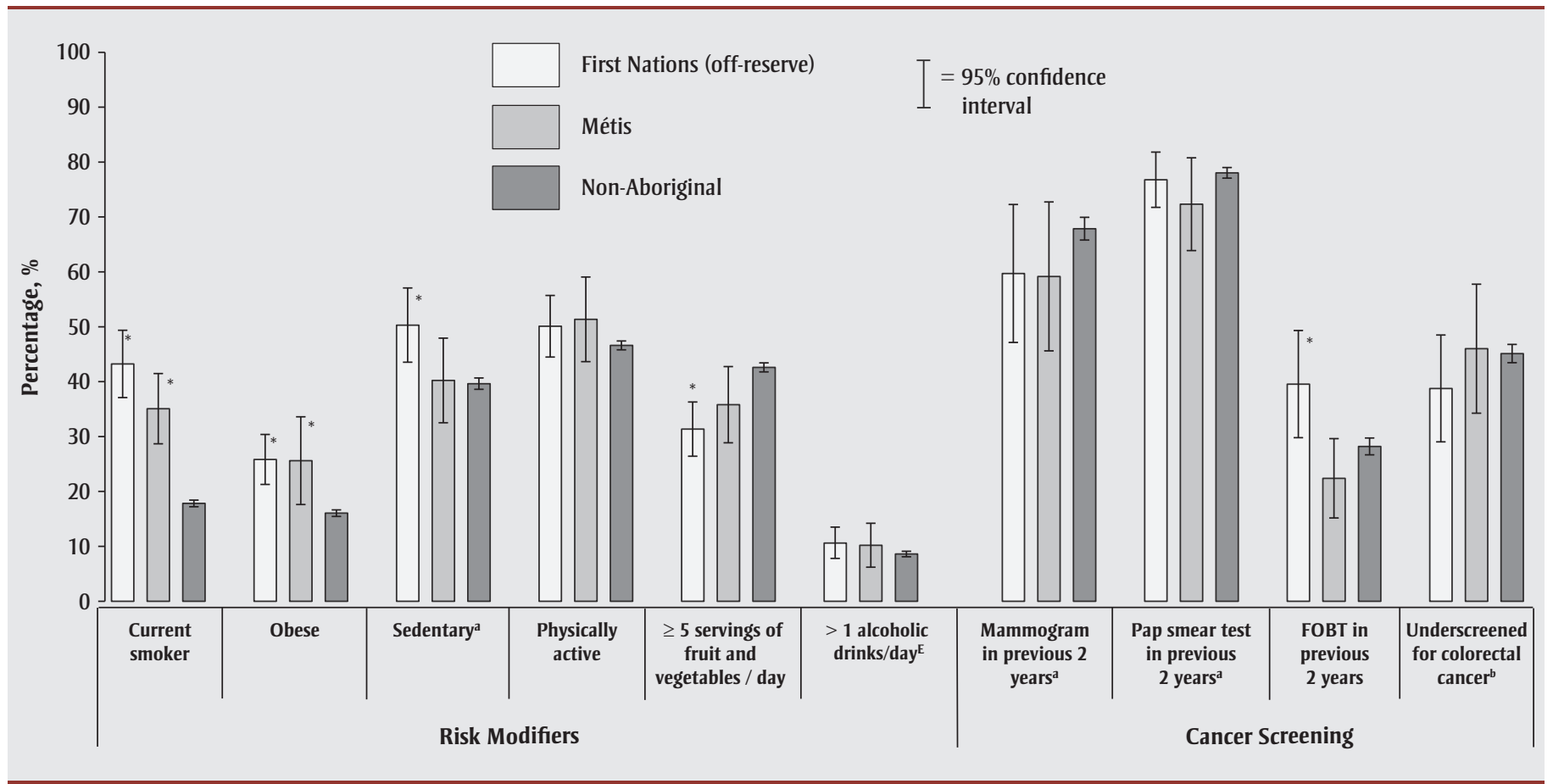

Source: Canadian Community Health Survey (2007-2011 combined), Statistics Canada.

Abbreviations: CCHS, Canadian Community Health Survey; FOBT, Fecal Occult Blood Test.

Notes: All estimates are age-standardized to the 2006 Ontario Aboriginal identity population. Estimates represent the adult population ( $\geq 18$ years) with the exception of the following

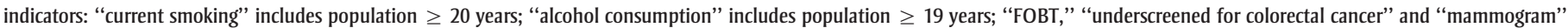
include population aged 50-74; "Pap smear test" includes population aged 21-69 years.

${ }^{a}$ Not included in the 2009 and 2010 CCHS surveys. Estimates for these indicators represent 2007, 2008 and 2011 CCHS combined data.

${ }^{\mathrm{b}}$ Represents the percentage of respondents who have not had either of an FOBT in the previous 2 years or a colonoscopy and/or sigmoidoscopy in the previous 10 years.

${ }^{\mathrm{E}}$ Estimate for Métis should be interpreted with caution. Coefficient of variation is between $16.6 \%$ and $33.29 \%$.

${ }^{*}$ Based on non-overlapping confidence intervals, estimate is significantly different from non-Aboriginal estimate for the corresponding risk factor.

lower and cervical and breast cancer screening rates similar to our findings. ${ }^{26}$

By pooling responses from 5 CCHS, we were able to produce reportable prevalence estimates specific to Ontario First Nations and Métis, a strength of this work. The cost of this approach, however, is that the estimates represent an average prevalence over time rather than the most recent health status of the populations.

Finally, because of the self-reported nature of the survey, our results may be subject to social desirability bias whereby survey respondents tend to under-report behaviours that are socially undesirable and over-report those considered desirable.
Arguably, this effect would be similar across cultural groups and would not significantly affect the relative prevalence of any risk factor.

Despite these limitations, the analyses we present in this study show that the CCHS can provide risk factor estimates for Ontario's off-reserve First Nations, Métis and non-Aboriginal population with consistent indicators across populations. Further, by assessing specific cancer-related risk factors such as sedentary behaviour, cancer screening uptake and alcohol consumption measured in relation to cancer prevention guidelines, this paper provides new evidence on the health status of Ontario's First Nations and Métis population, specifically as it relates to cancer risk.

\section{Conclusion}

Estimating the prevalence of risk factors and uptake of cancer screening in the First Nations and Métis is essential for the planning and provision of primary and secondary prevention services to this population. To monitor trends and identify targets for intervention, analyses such as this should be repeated over time. The increased prevalence of chronic disease risk factors among First Nations and Métis reported here supports provincial recommendations that culturally appropriate and specific actions be taken to address these factors to reduce the burden of cancer in particular and chronic disease more generally in this and future generations. $^{41}$ 


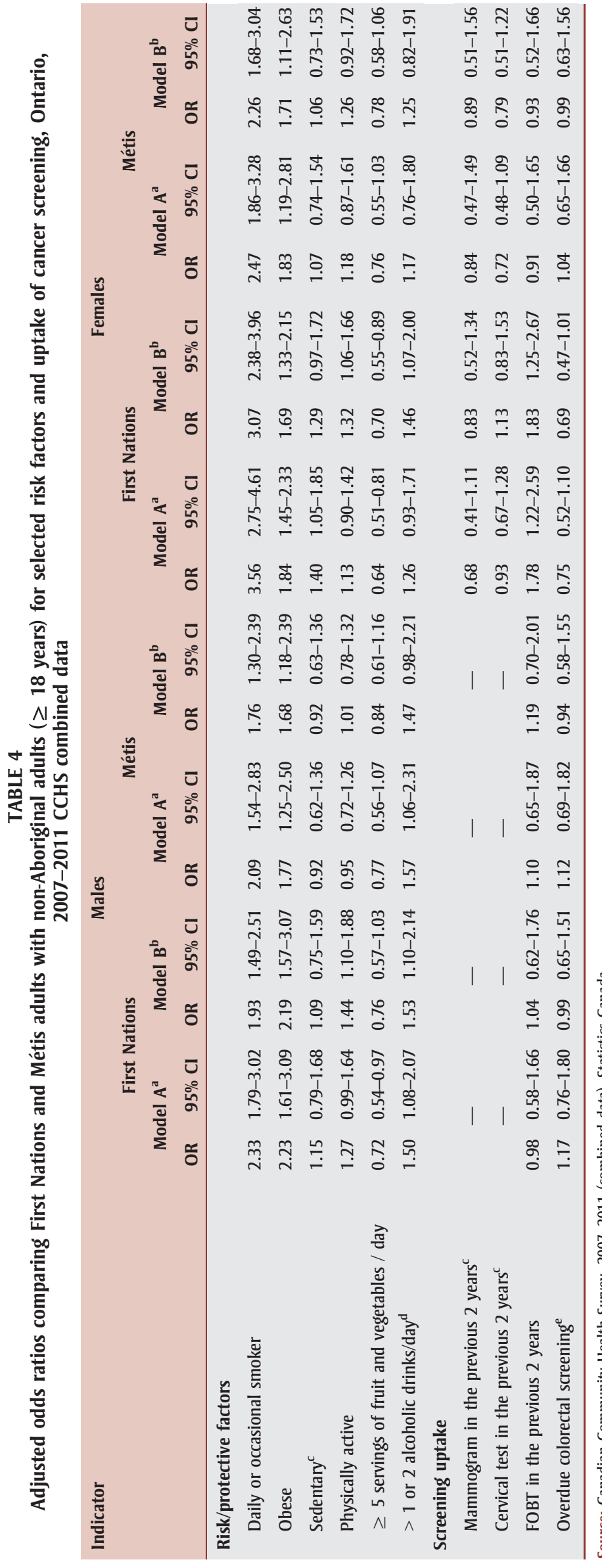

\section{References}

1. Tjepkema M, Wilkins $\mathrm{R}$, Senécal $\mathrm{S}$, Guimond E, Penney C. Mortality of Métis and Registered Indian adults in Canada: an 11-year follow-up study. Health Rep. 2009 Dec [Statistics Canada, Catalogue No.: 82003-X].

2. Health Council of Canada. The health status of Canada's First Nations, Métis and Inuit peoples [Internet]. Toronto (ON): Health Council of Canada; 2005 Jan [cited 2013 Jul 10]. Available from: http://publications .gc.ca/collections/collection_2012/ccs-hcc /H174-37-2005-1-eng.pdf

3. Canadian cancer statistics 2013 [Internet]. Ottawa (ON): Canadian Cancer Society; 2013 May [cited 2014 Jan 2]. Available from: http://www.cancer.ca/en/cancer-information /cancer-101/canadian-cancer-statistics -publication/?region = on

4. Waldram JB, Herring DA, Young TK. Aboriginal health in Canada: historical, cultural, and epidemiological perspectives. $2^{\text {nd }}$ ed. Toronto (ON): University of Toronto Press; 2006.

5. National Household Survey, 2011: Aboriginal peoples in Canada: First Nations People, Métis and Inuit [Internet]. Ottawa (ON): Statistics Canada; 2013 [Statistics Canada, Catalogue No.: 99-011-X2011001]. Available from: http://www12.statcan.gc.ca /nhs-enm/2011/as-sa/99-011-x/99-011-x2011 001-eng.cfm

6. Gionet L, Roshanafshar S. Select health indicators of First Nations people living off-reserve, Métis and Inuit. Health at a Glance. 2013 Jan [Statistics Canada, Catalogue No.: 82-624-X].

7. National Cancer Institute (NCI). Tobacco facts [Internet]. Bethesda (MD): National Cancer Institute; 2013 [cited 2013 Jul 13]. Available from: http://www.cancer.gov /cancertopics/tobacco/smoking

8. National Cancer Institute (NCI). Obesity and cancer risk [Internet]. Bethesda (MD): National Institutes of Health; 2012 [updated 2012 Jan 3; cited 2013 Jul 13]. Available from: http://www.cancer.gov /cancertopics/factsheet/Risk/obesity 
9. National Cancer Institute (NCI). Physical activity and cancer [Internet]. Bethesda (MD): National Cancer Institute; 2009 [updated 2009 Jul 22; cited 2013 Jul 13]. Available from: http://www.cancer.gov/cancertopics/factsheet /prevention/physicalactivity

10. Cancer Research UK. Diet and cancer: the evidence [Internet]. London (UK): Cancer Research UK; 2009 Sep 25 [cited 2013 Jul 13]. Available from: http://www.cancerresearchuk .org/cancer-info/healthyliving/dietandhealthy eating/howdoweknow/diet-and-cancer-the -evidence

11. National Cancer Institute (NCI). Alcohol and cancer risk [Internet]. Bethesda (MD): National Cancer Institute; 2013 [updated 2013 Jun 24; cited 2013 Jul 13]. Available from: http://www.cancer.gov/cancertopics /factsheet/Risk/alcohol

12. Lynch BM. Sedentary behavior and cancer: a systematic review of the literature and proposed biological mechanisms. Cancer Epidemiol Biomarkers Prev. 2010;19(11): 2691-709.

13. Statistics Canada. Other reference periods Canadian Community Health Survey Annual Component [Internet]. Ottawa (ON): Statistics Canada; [cited 2013 Nov 3]. Available from: http://www23.statcan.gc.ca $/ \mathrm{imdb} / \mathrm{p} 2 \mathrm{SV} . \mathrm{pl}$ ?Function $=$ getInstanceList $\&$ SurvId $=3226 \&$ SurvVer $=2 \&$ InstaId $=15282 \&$ SDDS $=3226 \& l a n g=e n \& d b=i m d b \& a d m=$ $8 \&$ dis $=2$

14. Thomas S, Wannell B. Combining cycles of the Canadian Community Health Survey. Health Rep. 2009;20(1):53-8.

15. Cancer Care Ontario. Mammograms [Internet]. Toronto (ON): Cancer Care Ontario; [modified 2012 Oct 18; cited 2013 Jul 16]. Available from: http://www.cancercare.on.ca/pcs/screening /breastscreening/mammograms/

16. Screening guidelines [Internet]. Toronto (ON): Cancer Care Ontario; [modified 2013 Apr 24; cited 2013 Jul 16]. Available from: http://www.cancercare.on.ca/pcs/screening /cervscreening/screening_guidelines/

17. About colorectal cancer screening [Internet]. Toronto (ON): Cancer Care Ontario; [modified 2011 May 3; cited 2013 Jul 16]. Available from: http://www.cancercare.on.ca/pcs /screening/coloscreening/aboutcolscreening/
18. Association of Public Health Epidemiologists in Ontario (APHEO). 5A Smoking Status [Internet]. Toronto (ON): Association of Public Health Epidemiologists in Ontario; 2009 [updated 2009 Jun 29; cited 2013 Jul 9]. Available from: http://www.apheo.ca /index.php?pid $=117$

19. World Cancer Research Fund/American Institute for Cancer Research. Food, nutrition, physical activity, and the prevention of cancer: a global perspective. Washington (DC): World Cancer Research Fund/ American Institute for Cancer Research; 2007.

20. Statistics Canada. Canadian Community Health Survey (CCHS) Annual Component - 2011 Questionnaire. Ottawa (ON): Statistics Canada; 2011 [cited 2013 Jul 9]. Available from: http://www23.statcan .gc.ca/imdb-bmdi/instrument/3226_Q1_V8 -eng.pdf

21. Garner R, Carrière G, Sanmartin C, Longitudinal Health and Administrative Data Research Team. The health of First Nations living off-reserve, Inuit, and Métis adults in Canada: the impact of socioeconomic status on inequalities in health. Health Research Working Paper Series. 2010 Jun [Statistics Canada, Catalogue No.: 82-622-X].

22. Lix LM, Bruce S, Sarkar J, Young TK. Risk factors and chronic conditions among Aboriginal and non-Aboriginal populations. Health Rep. 2009;20(4):21-9. [Statistics Canada, Catalogue No.: 82-003-XPE].

23. Reading CL, Wien F. Health inequalities and social determinants of Aboriginal people's health [Internet]. Prince George (BC): National Collaborating Centre for Aboriginal Health; 2009 [cited 2013 Jul 16]. Available from: http://www.nccah-ccnsa.ca/docs /social\%20determinates/nccah-loppie-wien _report.pdf

24. Withrow D, Kewayosh A, Marrett L. Cancer in the Métis nation of Ontario: clinical significance report [Internet]. Ottawa (ON): Métis Nation of Ontario; 2012 Mar [cited 2013 Jul 16]. Available from: http:// www.metisnation.org/media/229177/mno $\% 20$ cancer $\% 20$ clinical $\% 20$ significance $\% 20$ report $\% 20 \% 2829$-mar-2012\%29.pdf
25. First Nations Regional Longitudinal Health Survey (RHS) 2002/03 - Results for Adults, Youth, and Children Living in First Nations Communities. Ottawa (ON): The First Nations Information Governance Centre; 2005 Nov.

26. First Nations Regional Health Survey (RHS) Phase 2 (2008/10) National Report on Adults, Youth and Children Living in First Nations Communities. Ottawa (ON): The First Nations Information Governance Centre; 2012 Jun.

27. Cancer Care Ontario. Aboriginal Cancer Strategy II [Internet]. Toronto (ON): Cancer Care Ontario; [cited 2013 Jul 22]. Available from: https://www.cancercare.on.ca/common $/$ pages $/$ UserFile.aspx?fileId $=138007$

28. Marrett LD, Chaudhry M. Cancer incidence and mortality in Ontario First Nations, 19681991 (Canada). Cancer Causes Control. 2003;14:259-68.

29. Kelly J, Lanier A, Santos M, et al. Cancer among the circumpolar Inuit, 1989-2003. II. Patterns and trends. Int $\mathrm{J}$ Circumpolar Health. 2008;67(5):408-20.

30. Zhao J, Halfyard B, Roebothan B, et al. Tobacco smoking and colorectal cancer: a population-based case-control study in Newfoundland and Labrador. Can J Public Health. 2010;101(4):281-9.

31. Statistics Canada. Canadian Community Health Survey: overview of Canadians' eating habits. [Internet]. Ottawa (ON): The Daily; 2006 Jul 6 [cited 2013 Jul 16]. Available from: http://www.statcan.gc.ca /daily-quotidien/060706/dq060706b-eng.htm

32. Cancer Care Ontario. Breast cancer screening [Internet]. Toronto (ON): Cancer Care Ontario; 2012 Nov 28 [cited 2013 Jul 16]. Available from: https://www.cancercare .on.ca/pcs/screening/breastscreening/?WT .mc_id $=/$ obsp

33. Elias B, Kliewer EV, Hall M, et al. The burden of cancer risk in Canada's indigenous population: a comparative study of known risks in a Canadian region. Int J Gen Med. 2011;4:699-709.

34. Quan H, Fong A, De Coster C, et al. Variation in health services utilization among ethnic populations. CMAJ. 2006;174(6):787-91. 
35. Demers AA, Kliewer EV, Remes O, et al. Cervical cancer among Aboriginal women in Canada. CMAJ. 2012;184(7):743-44.

36. Sattler P. "Let's Take a Stand Against...Colorectal Cancer!” Evaluation report [Internet]. Toronto (ON): Cancer Care Ontario; 2011 May [cited 2013 Jul 16]. Available from: https://www.cancercare.on.ca /cms/one.aspx?objectId $=37272 \&$ contextId $=$ 1377

37. Macaulay AC. Improving aboriginal health: how can health care professionals contribute? Can Fam Physician. 2009;55(9):3349.

38. Mitura V, Bollman RD. The health of rural Canadians: a rural-urban comparison of health indicators [Internet]. Ottawa $(\mathrm{ON})$ : Rural and Small Town Canada Analysis Bulletin, 2003 Oct [cited 2013 Jul 16]. [Statistics Canada, Catalogue No.: 21-006XIE]. Available from: http://www.statcan .gc.ca/pub/21-006-x/21-006-x2002006-eng .pdf

39. King $M$, Smith A, Gracey M. Indigenous health part 2: the underlying causes of the health gap. Lancet. 2009;374(9683):76-85.

40. National Heart, Blood and Lung Institute (NHLBI). What causes overweight and obesity? [Internet]. Bethesda (MD): National Heart, Blood and Lung Institute; 2013 Jul 13 [cited 2013 Jul 16]. Available from: http://www.nhlbi.nih.gov/health /health-topics/topics/obe/causes.html

41. Manson H, Rabeneck L, Allison KR, et al. Taking action to prevent chronic disease: recommendations for a healthier Ontario. Toronto (ON): Ontario Agency for Health Protection and Promotion, Cancer Care Ontario; 2012. 